European journal of American studies

Special Issue: Video Games and/in American Studies:

Politics, Popular Culture, and Populism

\title{
Ludic Populism and Its Unpopular Subversion
}

\section{Sascha Pöhlmann}

\section{(2) OpenEdition}

\section{Journals}

Electronic version

URL: https://journals.openedition.org/ejas/17259

DOI: 10.4000/ejas. 17259

ISSN: 1991-9336

Publisher

European Association for American Studies

\section{Electronic reference}

Sascha Pöhlmann, "Ludic Populism and Its Unpopular Subversion", European journal of American studies [Online], 16-3 | 2021, Online since 09 September 2021, connection on 17 September 2021. URL: http://journals.openedition.org/ejas/17259 ; DOl: https://doi.org/10.4000/ejas.17259

This text was automatically generated on 17 September 2021.

Creative Commons License 


\title{
Ludic Populism and Its Unpopular Subversion
}

\author{
Sascha Pöhlmann
}

\section{Video Game Politics}

1 Video games are political. It is painful to have to insist on this fact, but the necessity of such insistence indicates the dimensions of the problem. My nod to Judith Fetterley's "On the Politics of Literature," the introduction to her classic second-wave feminist study The Resisting Reader, serves not only to contextualize my own modest project in a much larger tradition of cultural critique but also to indicate that the political aspects of video games are still woefully neglected today, to the point where their being political is all too often denied in the first place. The study of video games and popular gamer culture is haunted by the same specters of the apolitical that Fetterley once found necessary to exorcise from the study of American literature, and the implications of that paratactic opening statement are neither trivial nor self-evident. Instead, as both journalistic and academic video game criticism are increasingly taking on the task of exploring what it means to say that video games are political, ${ }^{1}$ these explorations meet with strong resistance against the premise itself. Eugen Pfister puts it succinctly in the opening paragraphs of his commendable essay "'Keep Your Politics out of My Games!" when he states that for such players, the political is "understood as a stain, as something corrupting the fun." ${ }^{2}$ As such, video games are no different from many other areas of popular culture whose exponents routinely highlight their entertainment value rather than their functional, political, or ideological role, be it comic books or football. Like in all those areas of popular and indeed also high culture, these claims to the exclusive primacy of aesthetics over politics, if not the outright rejection of any political content or relevance whatsoever, are political themselves in their desire to construct an apolitical sphere that is not 'tainted' by its corrupt opposite.

2 Yet while the political relevance of popular culture in general has been almost a given in the long discursive tradition of the concept and its academic study, ${ }^{3}$ the politics of 
video games is still a more fundamentally contested territory. The borders of this particular magic circle are quite heavily policed by those who believe that a game is just a game, and that it is and should be separate from the reality in which it is played. Perhaps the nature of play somewhat lends itself to a stronger insistence on such a clear-cut separation than other cultural forms, as it seems to be the result of an ontological difference. As Johan Huizinga remarks in his groundbreaking theorization of play:

All play moves and has its being within a playground marked off beforehand either materially or ideally, deliberately or as a matter of course. ... The arena, the cardtable, the magic circle, the temple, the stage, the screen, the tennis court, the court of justice, etc., are all in form and function play-grounds, i.e. forbidden spots, isolated, hedged round, hallowed, within which special rules obtain. All are temporary worlds within the ordinary world, dedicated to the performance of an act apart. (10)

3 This ontological demarcation can indeed be a way of delineating the limits of the political, and if it is not quite a border between the political and the apolitical, then it is at least a point of transformation where the political changes, where its rules shift, or where it can be reimagined. Yet this distinction between game and not-game is just as blurry as that between fiction and nonfiction, and Mia Consalvo's concise judgment applies in this case as well: "There is no magic circle." Nevertheless, Stephanie Boluk and Patrick LeMieux are right in pointing out that "even if the magic circle does not exist, the desire for an ahistorical, escapist gamespace continues to govern the standard metagame and the ideological avatar of play" (21). It is still necessary to insist -and keep insisting-that games "are not isolated formations, fundamentally separated from culture and its dominant ideologies" (Murray 39).

Still, the argument that video games are not political must be taken seriously if only because it cannot be refuted by a simple insistence that everything is political, as such a universal claim would utterly render the term quite meaningless. At the same time, it is crucial to make the term meaningful by giving at least a working definition, and one can hardly be explicit enough about this, given the ambiguity of the concept. Such a definition must allow for a distinction between the political and the nonpolitical, which could then be used to ask first whether there are apolitical spheres of culture, and then whether or not video games and gamer culture are part of such a sphere. My own approach is more positive, however, as I will describe and analyze a particular aspect of video games that I consider to be highly political, not so much in the interest of confirming my opening statement but rather with the goal of showing at least one among many other ways in which this statement is true. Generally, video games arelike any other cultural product-both a site of ideology and of its contestation, not necessarily in a direct sense of conveying an explicit political message as propaganda but rather in the sense of conveying implicit and normative assumptions about the world. In the following, I will consider a concrete example of this by asking whether we may consider some video games to be populist.

In asking this question, I am not using this ambiguous term to denote games that cater to a mass audience, as this meaning is well covered by the term "popular" rather than "populist" (although the latter perhaps only describes polemically what is perceived as an excessive degree of catering to the projected desires of a mass audience, represented for example by the hierarchical distinction between casual and hardcore gaming). ${ }^{4}$ The history of video games certainly exhibits a tendency to make them more accessible and 
popular, yet this is an issue of consumability ${ }^{5}$ rather than actual populism in the stricter political sense, and it is interesting mostly for its replication of discourses of elitism that are usually associated with high culture. What I am concerned with here instead is how some video games employ a populist imagination in constructing "the people" while others resist or subvert this populist imagination, and I will argue that this dialectic is one notable site of the political with regard to the medium (and one that video game criticism has yet to address at all). I am especially interested in cases when this construction and subversion takes place in the same game, by way of dissonances between its representational elements-images, sound, text, narrative aspects-and the gameplay itself; in short, in games that undermine their own populist aesthetics (thus my title of "ludic populism and its unpopular subversion"). I therefore understand the political not only as the way power is distributed within a community or between communities but also as how such communities are imagined and constituted through symbolic practices, and how they are constructed as political units in the first place, which then may become political actors or sites of political action. If politics is, as Jacques Rancière has it, "first of all a way of framing, among sensory data, a specific sphere of experience" (10), the imaginary constitution of communities as something to be perceived and experienced is a central aspect of the political. One might add that video games resonate particularly well with this political "intertwining of being, doing, and saying that frames a polemical world" (10) because of their unique way of combining these three aspects in their medial form.

Notably, the imagination of "the people" is one of the most fundamental elements of modern politics itself, and thus an inquiry into how "the people" are constructed in cultural artifacts necessarily draws attention to their political aspects. ${ }^{6}$ An imagination of "the people" as a political sovereign is indispensable to democratic systems as well as to totalitarian ones, and in any case this imagination is haunted by the unruliness of the concept, its productive and dangerous ambiguity, since the term either means many different things or designates something that is quite impossible to define in a concrete sense. Here, I am interested in "the people" especially in the way the concept is used in contemporary populist discourses in the US and elsewhere, namely to indicate a homogeneous collective instead of a political actor that is basically a necessary fiction. ${ }^{7}$ In the most general sense, I claim that any imagination of "the people" is populist, just like any imagination of "the nation" is nationalist, and that both people and nation are the discursive products of populism and nationalism instead of their foundation. ${ }^{8}$ Yet there are great qualitative differences as to the degrees and forms these populist imaginations take. Margaret Canovan rightly insists that "'the people' as an entity or group capable of exercising power is/are not readily available. Far from being a given, it/they has/have to be in some way constructed, mobilized or represented to be in a position either to wield power or to be checked in doing so" (88-89). This is the case for both an imagination of "the people" as the democratic sovereign in purely political terms as much as that of a homogeneous collective whose coherence is based on an allegedly prediscursive identity. The difference between these extremes-the fictional political sovereign and the essentialized ethnic community-is striking, and yet they find in "the people" an imaginary contact zone where the conflation becomes more than conceptual and has very material political consequences. Indeed, contemporary populism is often based on the refusal to see these as distinct imaginations at all. It is true that populism is "a particular moralistic imagination of politics ... that sets a morally pure and fully unified-but ... ultimately 
fictional-people against elites who are deemed corrupt or in some way morally inferior" (Müller 19-20). Yet I insist that this imagination is not just moralistic but racial as well, and that contemporary populism is indeed what can best be described by a German term that populism only pretends to reject: it is völkisch, a fantasy of homogeneity that is exceptionalist, essentialist, racial and racist. This is precisely the identitarian element that sets such populism apart from an imagination of 'the people' as the democratic sovereign that can do without any such aspect.

These extremes frame the imagination of "the people" in any cultural artifact, and these are the terms in which I propose to analyze a set of exemplary video games that either involve or even need a conceptualization of "the people" as their ludic premise. Simply put, I want to take a look at how video games imagine "the people," and to which ends. This involves a consideration of their aesthetics-how "the people" are presented as such-as well as of their ludic aspects-the gameplay function of "the people." I will explore whether some video games may be legitimately called "populist" in the sense that they proffer an imagination of "the people" as a unified collective "without fundamental internal divisions" (Mudde 68), and I will also explore how other games (or indeed the same games) instead "pierce the populist fantasy of a fully united, homogeneous people" (Müller 114). Video games are particularly relevant for such an analysis of a populist imagination and anti-populist resistance because of their unique interactivity, so that player agency is always an integral part of their aesthetics and, by extension, also their politics. Video games not only represent the people in a certain way but allow or force the player to act toward the people, to act as the people or for the people (or against them). This agency may support or subvert the ideological "content" of the representation, especially since agency and power are other crucial elements of populist discourse.

\section{Playing with the People: Strategy Games}

Where do players encounter "the people" in video games, and how do they get to act in relation to them? Let me first consider the genre that is most explicitly about politics itself, the strategy game. Any simulation of politics is highly significant in its process of abstraction, in the ways it necessarily simplifies the complexities of reality in order to turn it into a system that reacts to player input and provides them with an output that is, for the sake of fun, neither predictable nor uncomputable. Processes of power distribution seem to be harder to simulate than others, since the discursive core of politics (with its very material consequences) is not as easily broken down into numbers for algorithmic operations. ${ }^{9}$ This is not so much an issue of mimetic "realism" but rather of in-game consistency, and the discursive aspects of politics (representation, arguments, negotiations, rhetoric, etc.) generally resist the matrix of cause and effect that allows for effective abstraction in other cases.

Perhaps for this reason, many games that seem to be political simulations really turn out to be something else. For example, one of the first games of the genre, Kaiser (1984), is an economic simulation rather than a political simulation, and its goal of rising to political power is achieved mainly by economic means. Other simulations such as the Sim City series (1989-) focus on the aspect of urban planning rather than urban politics, and still others (such as Populous [1989], Black \& White [2001], or From Dust [2011]) take a different route and imagine "the people" only from an explicitly godlike perspective. 
All these games are relevant for how they reduce or avoid the political aspects of what they are simulating, and the politics of this imagination of the apolitical surely would merit an extensive analysis of its own, yet I can only address them here to contextualize those games that are more complex in their populism. Such simulations are notable in their marginalization of the people as both a political force and a collective. For example, there are "citizens" in the original Sim City, and they make demands and pay taxes, but they are no more than a "population," and their political agency is reduced to an opinion poll about whether or not the mayor is doing a good job. As such, these games may be classified as populist in that they homogenize "the people," yet since they do this in order to marginalize rather than empower them within the gameplay framework, their populism is much less prominent and relevant than in games that actually incorporate "the people" as an integral audiovisual, narrative, and/or ludic element. The aforementioned Civilization series (1991-) is a more complex example of such populism, as it stands in the tradition of these simulations that avoid politics but nevertheless makes forays into its sphere in various ways. Its subgenre of the $4 \mathrm{X}$ simulation (explore, expand, exploit, exterminate) is particularly relevant in this regard, as it usually involves large-scale strategies based on collective political actors rather than individual ones.

10 As part of this $4 \mathrm{X}$ simulation, the Civilization series continually evolved its gameplay mechanic of diplomacy to simulate the discursive aspects of politics, but this is not the most salient aspect of how the game imagines and represents politics to its players. The increasing complexity of this (still quite basic) feature is less relevant than how it constructs political action more generally, as it is something that occurs between distinct groups but not so much within them. In other words, players get to negotiate internationally but not intranationally, and they may dictate internal policies that have a statistical effect on the population as such, but not on any distinct parts of it. The basic geopolitical actors in Civilization in terms of its representational and gameplay aspects are distinct, homogeneous, and transhistorically stable groups of people, and the game is populist in imagining community that way..$^{10}$ Players start the game by choosing a "civilization"-each with slightly different properties, bonuses, or unitsand then guiding it through history to victory, which can be achieved in various ways. "Civilization" is the most common term the game uses for the groups it constructs, but it employs related terms such as "nation," "country," or "people" as synonyms without distinction. Consider the American civilization in Civilization V (2010) as an example, where players are greeted and named as its "leader":

Welcome President Washington! You lead the industrious American civilization! Formed in the conflagration of revolution in the 18th century, within a hundred years, the young nation became embroiled in a terrible civil war that nearly tore the country apart, but it was just a few short years later in the 20th century that the United States reached the height of its power, emerging triumphant and mighty from the two terrible wars that destroyed so many other great nations. The United States is a nation of immigrants, filled with optimism and determination. They lack only a leader to help them fulfill their promise.

President Washington, can you lead the American people to greatness? Can you build a civilization that will stand the test of time?

The goal, then, is to "lead the American people to greatness," which means competing with other peoples to fulfill one of the victory conditions in the game as they progress from the Ancient era to the Information age (with the expansion Gods \& Kings [2012]). Therefore, in Civilization, human history is the history of different homogeneous 
peoples, and while they interact in various ways, they never merge. Each civilization starts with a different set of traits, ${ }^{11}$ and there is no gameplay mechanic to adopt another civilization's traits in any way. Thus they remain both homogeneous and distinct as geopolitical gameplay actors at all times. In this sense, the game offers a radically ethnopoluralist ${ }^{12}$ vision that prohibits multiculturalism: there are different peoples in the world, all of them culturally homogeneous and ethnically distinct, and they should not mix in any way. Any political or economic interaction happens between these actors, and the lines between them are as clearly drawn as the borders on the game map and their binary system of territoriality, where a tile cannot be shared by two or more powers. The homogeneity of the people is confirmed rather than disturbed by the way they are represented to players in-game: The social policies that players implement will grant them gameplay bonuses but not actually affect the people except for the very general modifier of "happiness," and the people never exhibit any significant internal differences over time or at any moment that players would actually have to consider in their policymaking. Neither elected nor part of the people themselves, players can rely on the people as a transhistorically stable entity that never has to be managed in its difference but only as a whole, and even then only as a resource for other goals. Civilization $V$ thus offers an extreme populist fantasy in which "the people" are a given but in their stability fully under control, a political tool rather than itself the subject or object of politics.

12 And yet this is only half the story of Civilization $V$, and the game itself subverts its own populism through its gameplay. This subversion can be described in terms of an unpopular culture that actually stages the people as missing instead of present. This is an intensification of the absence of the people from earlier games such as Kaiser or Sim City, only that now this absence is even more palpable because it is framed by the alleged presence and centrality of the people. In other words, Civilization $V$ seems to be about the people but really is not; it initially places them center-stage by means of visual and textual representation but then really plays around them. While the people appear to be the basic unit of geopolitical action in the game, they are actually entirely absent from the game itself, and the real actor is their leader, the players, who remain outside of the in-game time. The only people of consequence in the game are very few "individuals"-specialists, advisors, functions without names-but never the people as a group, not even as the most abstract of homogeneous masses, and never as a multitude of individuals that only barely coheres into the fiction of the people as a political actor. The people in Civilization V are simply of no consequence; the happiness of "citizens" in the cities is an important aspect of the gameplay, but this is about as much as the people matter in the game, and they certainly do not matter as a people. Thus the game subverts its own populist aesthetic by first implying that the people are homogeneous and timeless and then to render them utterly meaningless in its gameplay. They are taken out of the political equations rather than complicating them as a variable in the overall simulation. The implication, then, is that geopolitical action is not popular action, and politics is actually independent of such categories of identity (although its rhetoric may well exploit them). After all, it does not matter which civilization the players pick, as they are, fundamentally, all the same, except for the few bonuses here and there that provide variety but not imbalance, so that the game can be won or lost with any civilization in any constellation. 

include the people more prominently as they construct the political. These games are notable for their different ways of avoiding the pitfalls of populism in imagining "the people" as a political entity. Instead of embracing a populist fantasy of homogeneity, which would certainly be easier to simulate, they pierce it by insisting on diversity so that "the people" are not a unified political actor but become the heterogeneous subject of politics itself. This is the most effective strategy of the unpopular ludic subversion of populism: show that "the people" are never self-identical and that their very heterogeneity necessitates politics to manage difference rather than express a unified will. Such management is the central aspect of the Democracy (2005-) and Tropico (2001-) series, although the games themselves are very different. The gameplay of Democracy 3 (2015) and Tropico 4 (2011) (and future instalments of both series) is all about keeping the people happy, and this is a task and goal in the first place because the people are not a unified whole that can be managed as such. Instead, politics in these games is geared toward juggling the radically different interests, identities, and opinions that are subsumed under the governmental fiction of "the people," and this diversity indicates just how fictional this unifying term is even on that level. As they draw on this discrepancy between the fiction of "the people" and a reality of complex and heterogeneous subject positions, both games employ a satirical mode of representation to different degrees, and they thus contain elements of critique of the very discourses they include in their simulation.

element is most pronounced in Tropico 4, which is basically a banana republic simulator that gleefully draws on stereotypical exaggeration in its political satire. The game casts players as "El Presidente" and enables them to build a Cold War island dictatorship that, in true populist fashion, pretends to be a democracy, even though every election comes with a fraud option, along with bribery and assassination to ensure the people are voting the right way. Notably, players can even choose the character trait of "populist" for a particular bonus in the game, described as follows:

You have made a meteoric ascent into politics with your ability to manipulate people by exploiting their cravings for change and a better life. You promised to represent the interests of the common Tropican against the wealthy power elite. Your rhetoric is spiced with full-blown phrases like 'justice', 'real reforms', and 'change'-but you're no different than the next demagogue. Your false promises are only valid until you've won the elections. Then you suddenly develop a case of Alzheimer's and forget what you've said.

Constant Effects: +10 respect with the Nationalists, no consequences from unfulfilled election promises.

15 The game satirizes populism directly in such descriptions and in the quotes that randomly appear in the loading screens, which often exemplify or comment upon the anti-elitist, homogenizing rhetoric that is the mark of populist leaders who claim to represent the true people as a whole while not being part of the elite themselves. ${ }^{13}$ This is a textual way of critiquing populist rhetoric by placing it in a ludic context that is all about staying in power and filling one's Swiss bank account along the way to any mission goal the game might offer.

Yet the more substantial critique of populism occurs in the gameplay itself, since the game's construction of "the people" is based on a complication of "the people." Like in Civilization, the players act as the powerful leader, but this time they really need to deal with "the people" as a political entity, and with the people as a set of individuals rather

European journal of American studies, 16-3 | 202 
than a singular group. As the players are told during the tutorial by Generalissimo Santana, "[c]itizens are the most important and the most dangerous resources of Tropico." Instead of "the people" being a singular variable in the political equation, they are a set of variables themselves, and the game conveys this complexity in two different ways. On the one hand, "the people" are represented by different factionscapitalist, communist, religious, intellectual, and so on-that each react differently to player actions, and their happiness is determined by a variety of related factors (housing, employment, entertainment, etc.). While this is certainly a reductive set of parameters that curbs the complexity of "the people" in order to simulate it, it is at least a set of parameters, and they imply that politics means managing "the people" in their heterogeneity rather than as a homogeneous group. The second aspect of this simulation of diversity is that "the people" are actually people, individuals with names, age, gender, desires, jobs, and social relations who may or may not support one or many of the factions mention above. As opposed to the $4 \mathrm{X}$ genre of Civilization, Tropico's city-building simulation allows for granular micromanagement, and the optimization of economic processes or traffic involves a close consideration of the conditions and interests of individuals, who may turn criminal, rebel, or leave the island if their needs are not addressed. Each member of the people is simulated in their differences, and this resists the populist myth of popular homogeneity. The camera perspective allows players to zoom in on the map to watch these individuals as they go about their lives, and clicking any of them reveals all sorts of information about them, thanks to the secret police. This ties in with the Orwellian aspects that Tropico explicitly includes in its satirical gameplay, and the info box is also the tool for players to have these individuals bribed, arrested, or assassinated for money. Yet it also emphasizes the heterogeneity of "the people" as the subject of politics that is quite capable of political action but does not exert this power in a unified way as "the people." ${ }^{14}$

This heterogeneity is taken a step further in Democracy 3. The game does not wear its satirical aspects on its sleeve like Tropico 4, but when its take on politics is humorous, its critique is often directed against populist aspects of it, and it goes even further in its diversification of "the people." For example, players get to choose different party names that include, in a nod to Monty Python, "The Peoples Party," "The Peoples Front," "The "Popular Front," and even "The Peoples Popular Party." The game's loading screen, which lists the tasks the program is allegedly carrying out while preparing the game, includes items such as "gerrymandering constituencies," "inventing the internet," "compiling misleading statistics," "preparing soundbites," "posturing on foreign policy," "patronizing the electorate," "pandering to the media," or "scheduling photo opportunities." The task of the game is in keeping with this satirical beginning, since the game does not really have much of a goal except to stay in office until the term limit without being removed by election or assassination. The game would therefore lend itself to simulating how populism as a rhetorical and political strategy might help the players be as popular as possible with the electorate, but it actually includes something that precludes a strategy of pure popularity: the people. Democracy 3 does not simulate populism but democratic politics, and the popularity of the players is tied to the happiness of the people, so that one actually has to do things to make or keep as many of them satisfied instead of merely promising to do so. Thus the game actually rejects populism by alluding to its rhetoric and then dismissing it as an actual political program in a democratic system. 

"there are a number of situations and concerns that you will need to deal with as soon as possible, while keeping an eye on the long term improvement of our citizen's quality of life." The basic policy screen indicates just how complex a task this is, as it visualizes a network of how certain aspects affect others positively or negatively to differing degrees, and how a variety of policies are received by which parts of the electorate. "The people" are fundamental to this system in their capacity as voters, but they are profoundly heterogeneous, and the game ensures that the term refers to a loose political collective rather than a unified identity. In fact, the voters are different from each other along so many lines that players may initially wonder how to keep anyone happy at all, and the gameplay accordingly revolves around managing difference rather than creating unity. There are twenty "voter types" that are used in the polls, including categories such as "retired," "patriot," "motorist," or "parent" that may overlap with most other categories. Furthermore, voters are placed on a spectrum rather than in binary terms, so that usually a person is neither socialist nor capitalist but, say, sixty percent socialist. As these categories intersect in various ways, the game offers a rather complex representation of the individual voter (or potential nonvoter), and their numbers add up to an electorate that is just as complex. This double diversity resists the homogenization of "the people" as anything more than the collective term for a radically heterogeneous group. Instead of supposing that "the people" are a singular political actor or are united by categories of identity, this stages the tension between Rousseau's volonté particulière and volonté générale, between the individual and general will. Mistaking any part of the people for all the people is a definite way of getting assassinated, and the game does not allow for populist politics as a winning strategy in its democratic system, so that its gameplay and its mode of representation both can be considered as ways of piercing the populist fantasy of homogeneity.

\section{Playing with the People: First-Person/Third-Person Shooters}

19 Even if political or quasi-political simulation games may be the genre that lends itself most to populism and its critique, this dialectic may potentially be present in any other genre, although it will literally play out differently in each case. In the last part of my analysis, I want to take a look at first-person and third-person shooters, probably the most popular genre of the twenty-first century, and one in which gameplay, representation, and narrative intersect in more complex ways than in others. The genre has certainly become more narrative in its single-player modes, but at the same time the freedom of increasingly open-world exploration has heightened the agency of the players, so that plot and action are potentially set at odds with each other. This is precisely the fault line that is most important to a consideration of ludic populism and its potential subversion in such games.

That conflict is very subdued in my first example, BioShock Infinite (2013), as it limits player agency for a more stringent narrative experience, and it is not an open-world shooter like my second and third examples, Just Cause 3 (2015) and Far Cry 4 (2014). BioShock Infinite does contain a noteworthy critique of populism, but it is a narrative rather than ludic critique, and as such it is less effective in subverting the fantasy of a coherent people, since players are not required to position themselves interactively

European journal of American studies, 16-3 | 2021 
within this dialectic of construction and subversion. Instead, they are confronted with populism as a plot element rather than a ludic element in the form of the Vox Populi, the group whose militant resistance against the oppressive, racist, and xenophobic regime of the Founders in Columbia seems not only just but also initially in line with Booker DeWitt's (and the players') agenda. Led by Daisy Fitzroy, the self-declared "voice of the people" opposes the elite of Comstock and his privileged few, uniting those who are marginalized due to their ethnicity or class. This effectively pits one populist narrative against another, as both the Vox and the Founders base their political ideologies on notions of "the people," only that they radically differ as to who constitutes them (or should): the Vox think of "the people" in terms of "the common people" versus an elite that exploits and disenfranchises them, while the Founders' notion of peoplehood is a mainly racial one based in nineteenth-century American white privilege. In their respective ways, both are making "the core claim of populism: only some of the people are really the people" (Müller 21). The game narrative sets up Comstock as an enemy and the Vox as allies, but it subverts this binary by making the players not a champion of the people, as one might expect given how this trope informs many a video game. Instead, the game's multiverse shifts to a timeline where Booker already was this champion as Fitzroy's martyred lieutenant, and players get to experience the disastrous results of this reality, in which the armed Vox fight the Founders in a brutal civil war. There is a possibility that the Vox encountered at first may have turned out differently in their timeline, but the actualized reality reveals them to be just as cynical and power-hungry as the Founders they oppose. They kill civilians in the name of the people, and Fitzroy, symbolically covered in blood, is prepared to murder the young son of industrialist Jeremiah Fink for the sake of "pulling up the weeds from the root," as she has it. ${ }^{15}$ Her populism is thus revealed to be as fraudulent as that of the Founders, despite their different foundations, and the game subverts both their fantasies of "the people" as a unified political actor rising up against the elite that oppress them and as a racial identity using said exclusion to exert power over those it deems inferior outsiders. The game also subverts the trope of the players liberating an oppressed people that is often used to great effect in order to frame and direct player agency in video games, for example in Homefront (2011) or Far Cry 3 (2012). It does so by subverting the notion that there are "the people" to begin with, and it implies instead that they are as much a rhetorical device of the revolutionaries as of those in power. BioShock Infinite does not devalue its own critique of racism and oppression that it proffers through the representation of the Founders and their identity politics, but it certainly contextualizes it further to imply that there is no neat binary opposition between the people and an elite in the different worlds of the game.

21 Yet this contextualization does not really involve the players, and their agency is framed so narrowly that they do not get to deliberately position themselves within and toward these complexities of clashing populisms. This is where truly open-world games make for more interesting material, as their representation of such populist political struggles clashes more openly with the ability of players to interact with the game world that is narrated in these terms. Just Cause 3 and Far Cry 4 are exemplary in this regard, and my argument is that both these games use their gameplay to deflate the populism that informs their representational aspect. As in Tropico or Democracy, the element of humor is also not to be disregarded here, since both games take themselves and their subject matter much less seriously than BioShock Infinite, and this allows for a 
more effective satirical mode that goes against the grain of the usual dead seriousness of populist fantasies. This is most pronounced in Just Cause 3, which features protagonist Rico Rodriguez as a "dictator removal specialist" whose overall strategy is to cause so much chaos that the regime is sufficiently destabilized, which in a very concrete sense means blowing up anything that is conveniently marked as belonging to the regime. ${ }^{16}$ In the third installment, Rico gets to liberate his home of Medici, a group of Mediterranean islands oppressed by General Di Ravello. His aim, as revealed in a cutscene after the second story mission "Time For An Upgrade" in conversation with his sidekick Mario Frigo, is to "show the people we can take back their cities and towns for them," to which Mario responds: "Whatever you do, we've got your back-and whatever you destroy, we'll rebuild." Rico's strategy is surely questionable in many ways, but most importantly it sets him up as the symbolic representative of the people acting in their stead for their own good. This is the representational logic of populism, which cannot exist "without someone speaking in the name of the people as a whole" (Müller 20). As revolutionaries, Mario and Rico presume to do just that as they engage in "a particular moralistic imagination of politics, a way of perceiving the political world that sets a morally pure and fully unified-but ... ultimately fictional-people against elites who are deemed corrupt or in some way morally inferior" (Müller 19-20). This populism constructs the fiction of the people in order to rebel against an actually oppressive government, but their justified revolutionary claims do not make them any less populist in their means. ${ }^{17}$ The civilians in the game offer soundbites that confirm this populist scheme of representing the people and taking action for them, affirming that this is a just cause by saying "Rico, bless you and all you have done for us. Run the general off our island and give Medici back to the people!" or "Rico, you've inspired us to take back our country. Viva la revolution!" The game thus implicates players in the populist imagination and represents it as accurate, since "the people" actually talk to Rico and affirm his claim to enact their will. Mario's words offer the validation of Rico's campaign by adding the people as the constructive component that works in harmony with, rather than opposition to, his destructive actions: "whatever you destroy, we'll rebuild" in a complementary movement of the people and their heroic male personification.

22 A comparable imagination of "the people" is included in Far Cry 4, with the marked difference that its protagonist is no CIA-sponsored dictator removal specialist but an American tourist, Ajay Ghale, who gets violently entangled in the politics of the Himalayan country of Kyrat as he visits to return his mother's ashes to their homeland. The opening cutscene frames Ajay's entry into Kyrat in terms of his dual identity that relates to notions of peoplehood and belonging that will become more prominent in the game: an American embassy official addresses him on the phone as "Mr. Ghale"pronounced ['geIl]-and tells him he can only process his visa application as an American citizen, since they have "no official records regarding [his] Kyrati citizenship." Darpan, the fellow passenger on the bus who is helping Ajay enter Kyrat, demands his passport, which Ajay hands over for him to insert a bribe, adding Kyrati money to the American document and thus symbolically blending the two aspects of Ajay's identity. At the border, the inspection results in a firefight between the Golden Path rebels on the bus and the soldiers at the checkpoint, with the eventual arrival of Pagan Min, the autocratic ruler of Kyrat. Min addresses the protagonist as Ajay Ghalepronounced ['ga:leI]-which recontextualizes his identity as Kyrati rather than American. This duality is relevant when Ajay enters the political turmoil of the 
rebellion and encounters the Golden Path as the populist revolutionary force that rises up against Min's decadent dictatorship, as it justifies Ajay's role as someone who acts for the people of Kyrat because he is one of them. This is a part of his identity he uncovers as the game progresses and has him side with the Golden Path in various missions, and like Rico, Ajay becomes an all-powerful champion of the people and the central active force in their liberation. The initial cutscene frames this agency in terms of identity rather than political representation, and it invites players to read peoplehood in ethnic terms rather than in purely political ones. In populist terms, players act for a unified but oppressed people against a corrupt elite, in this case a oneman elite of Pagan Min, and their individual actions are justified in the representational logic of populism that also informs the revolutionary efforts they join.

However, this is only half the story, and both Just Cause 3 and Far Cry 4 significantly and substantially subvert their respective populisms to such an extent that they may ultimately be interpreted as works that challenge rather than espouse a populist imagination of homogeneous peoplehood. In Far Cry 4, this occurs in representational terms as the Golden Path is disenchanted like the Vox Populi in BioShock Infinite in the end, and the populist rhetoric of the two leaders Amita and Sabal is revealed to be as harmful as anything they sought to resist. After completing the game, players get to see the effects of their actions as they sided with either of the two in their battle against each other, and none of the outcomes is morally positive in explicit reference to the concept of peoplehood. In keeping with the populist notion that only some people are really "the people," Sabal has Amita's soldiers executed while telling them: "You chose to fight your own people- When you sided with Amita, you chose to desecrate your own heritage and spit on the gods." He tells Ajay that "there must be a cleansing for us to move forward" and thus shows how directly the populist rhetoric of "the people" is connected to ethnic notions of identity that delineate the pure people. In contrast, Amita is shown ordering soldiers to round up all the children as she is, as Ajay poignantly observes, "forcing the people to join the Golden Path," and she justifies this by telling him that she is "sacrificing our liberties for peace later. You can either get in line or get out of the way." Both Amita and Sabal illustrate the material consequences of the normative construction of the unified people, and their actions imply that imagining a homogeneous people is not far from homogenizing the people through violence and "cleansing" them from any "impurities."

Yet this representational critique of the populist imagination is not even the most significant one, and both Just Cause 3 and Far Cry 4 mount an even more effective challenge through their gameplay. This is implicit in the former and explicit in the latter, as Pagan Min thoroughly dismisses any populist motivation in the players by telling them what truly fuels their actions in the game, and this applies to Ajay as much as Rico. The narrative elements of populism that have players fighting for the people against a corrupt elite are directly countered by the open-world gameplay that is based on individualism rather than political ideology. The high degree of agency granted to players opposes rather than supports the populist cause they allegedly support. Pagan Min tells Ajay at the end about his motivations, and his account has profound significance for an interpretation of the gameplay experience: "Yes, your father killed your half sister, and then your mother killed him in return. I simply continued where she left off. I've killed so many people for them. But then I realized, I was only using Lakshmana's death as an excuse to do whatever I wanted to do. Just as you use those ashes as an excuse to do whatever you want to do. God damn if it isn't fun." This 
dismisses any moralistic motivation of the players in their gameplay actions, and it indicates that these narrative elements-the populism as much as the motivating plot device of the ashes-are irrelevant to an open-world game that allows and invites players to do whatever they want to do, and have fun as they do it. Players may or may not care about the troubling populism of the Golden Path or the plight of the Kyrati people, but regardless of their attitude, neither of these aspects truly informs the game to such an extent that they really affect the gameplay experience. Instead, this experience is determined by a heroic individualism that enables players to act according to their wishes, and the cutscenes that diminish this agency are less central to the game than the open-world interaction that heightens it. Pagan Min points out that this is about power rather than any narrative justification, about doing whatever you want to do. In the intro cutscene, Min tells Ajay that "You and I are gonna tear shit up," and in the alternative ending that comes after the player has actually waited for Min after being asked to in the opening scene, Min tells him that "maybe now we can finally shoot some goddamn guns." Both these lines indicate the true motivation for the gameplay, and they reveal any narrative content as supplementary. This applies to Just Cause 3 as well, only that the subversion of narrative by gameplay is hinted at in the title: Rico's just cause is reinscribed as a short version of "just because," which is a more apt description of the players' motivation in the game. Rather than truly engaging with the populist revolutionary struggle, players are causing havoc just because they can, and the open-world exploration provides them with means of interaction that either really need no narrative justification or are even in contrast to it. Like Far Cry 4, Just Cause 3 is about "tearing shit up" and shooting some guns in a heavily stylized, over-the-top sandbox designed mainly for this purpose, and these gameplay elements are so thoroughly disconnected from the populist narrative framing that they subvert rather than affirm it. Instead of fighting for the people, then, we are fighting for ourselves, and this more than anything shows just how empty the rhetoric of populism is when confronted with the true motivation of our interaction with the game: God damn if it isn't fun.

\section{Conclusion: Playing against the People}

In summary, then, the video games considered here seem to be populist only to subvert said populism, and they do not stop at constructing "the people" without moving on to dismantling it again. They do so by either revealing this arbitrary constructedness itself or a complexity that goes against the grain of the simplification that is at the heart of populist rhetoric. In a way, video games parallel these simplifying aspects of populism in that they are better at ludic complexity than at narrative complexity, and they lend themselves to representations of "the people" that are as reductive as those offered by populists. However, the games I analyzed here counteract their own tendency toward abstraction in at least two ways: First, they use satire and exaggeration for their critique on a representational level, and second, they use the complexity of their gameplay to oppose their own representational simplifications. Thus, they offer a ludic critique of populism and enlist the players and their agency in it, and in doing so, they self-reflexively draw on their own narrative limitations rather than deny them. This, then, is one way in which the video games discussed above are political: In their various ways, they present their players with an imagination of "the people" and then force them to engage with this construction so that they will not act 
as or for the people but rather in such a way that fantasies of the unified and homogeneous people are dismantled because the players are playing. The controlled individualist aspect at the heart of this fantasy of agency surely merits a critique of its own, and it is no less political than the populist aspect it undermines. Yet this must not detract from just how effective such a fantasy is at doing so. After all, populism is such a serious business that both humor and playfulness should not be underestimated as ways of putting it out of that very business.

\section{BIBLIOGRAPHY}

BioShock Infinite. Irrational Games, 2013.

Boluk, Stephanie, and Patrick LeMieux. Metagaming: Playing, Competing, Spectating, Cheating, Trading, Making, and Breaking Videogames. U of Minnesota P, 2017.

Canovan, Margaret. The People. Polity, 2005.

Civilization V. Firaxis Games, 2010.

Consalvo, Mia. "There is No Magic Circle." Games and Culture, vol. 4, no. 4, 2009, pp. 408-417.

DeHaven, Tyler, and Chris Hendrickson. "The Vox Populi Group, Marx, and Equal Rights for All.” BioShock and Philosophy: Irrational Game, Rational Book, edited by Luke Cuddy, Wiley, 2015, pp. 114-26.

Democracy 3. Positech Games, 2013.

Dyer-Witheford, Nick, and Greig de Peuter. Games of Empire: Global Capitalism and Video Games. U of Minnesota P, 2009.

Far Cry 4. Ubisoft Montreal, 2014.

Fetterley, Judith. The Resisting Reader: A Feminist Approach to American Fiction. Indiana UP, 1978.

Ford, Dan. “'eXplore, eXpand, eXploit, eXterminate': Affective Writing of Postcolonial History and Education in Civilization V." Game Studies, vol. 16, no. 2, 2016, http://gamestudies.org/1602/ articles/ford. Accessed 18 April 2020.

Frank, Jason. Constituent Moments: Enacting the People in Postrevolutionary America. Duke UP, 2010. Huizinga, Johan. Homo Ludens: A Study of the Play Element in Culture. Routledge \& Kegan Paul, 1949. Just Cause 3. Avalanche Studios, 2015.

Juul, Jesper. A Casual Revolution: Reinventing Video Games and Their Players. MIT P, 2010.

Krause Knight, Cher. Public Art: Theory, Practice and Populism. John Wiley \& Sons, 2011.

Laclau, Ernesto. "Populism: What's in a Name?" Ernesto Laclau: Post-Marxism, Populism and Critique, edited by David Howarth, Routledge, 2015, pp. 152-64.

Lucat, Bertrand, and Mads Haahr. "Ideological Narratives of Play in Tropico 4 and Crusader Kings II." Proceedings of DiGRA 2015:Diversity of play: Games - Cultures - Identities. http://www.digra.org/ 
wp-content/uploads/digital-library/180_HaahrLucat_Ideological-Narratives-of-Play-inTropico-4-and-Crusader-Kings-II.pdf. Accessed 18 Apr. 2020.

Malkowski, Jennifer, and TreaAndrea Russworm, editors. Gaming Representation: Race, Gender, and Sexuality in Video Games. Indiana UP, 2017.

Müller, Jan-Werner. What Is Populism? Penguin, 2017.

Murray, Soraya. On Video Games: The Visual Politics of Race, Gender and Space. I.B. Tauris, 2017.

Nieguth, Tim, editor. The Politics of Popular Culture: Negotiating Power, Identity, and Place. McGill-

Queen's UP, 2015.

Pfister, Eugen. “"Keep Your Politics out of My Games!”' Spiel-Kultur-Wissenschaften. 8. Feb. 2018. https://spielkult.hypotheses.org/1566. Accessed 18 Apr. 2020.

Rancière, Jacques. “The Politics of Literature.” Substance, issue 103, vol. 33, no. 1, 2004. pp. 10-24.

Schubert, Stefan. "Dystopia in the Skies: Negotiating Justice and Morality on Screen in the Video Game BioShock Infinite." European Journal of American Studies, vol. 13, no. 4, 2018, https:// journals.openedition.org/ejas/14089. Accessed 18 Apr. 2020.

Street, John, Sanna Inthorn, and Martin Scott. From Entertainment to Citizenship: Politics and Popular Culture. Manchester UP, 2013.

Tropico 4. Haemimont Games, 2011.

\section{NOTES}

1. Nick Dyer-Witheford and Greig de Peuter's Games of Empire: Global Capitalism and Video Games (2009) is an important milestone in this development. More recent notable book-length publications in this regard include Soraya Murray's On Video Games: The Visual Politics of Race, Gender and Space (2017) as well as Gaming Representation: Race, Gender, and Sexuality in Video Games, edited by Jennifer Malkowski and TreaAndrea Russworm (2017).

2. Pfister's discussion in many ways provides the conceptual ground for my particular analysis here.

3. See for example Nieguth as well as Street, Inthorn, and Scott for recent studies on the politics of popular culture.

4. Jesper Juul usefully complicates this all too neat binary in his study A Casual Revolution.

5. Cher Krause Knight uses the term populist in such a positive, anti-elitist way when describing public art in terms of "the extension of emotional and intellectual, as well as physical, accessibility to the audience" (x).

6. Similarly, such an inquiry highlights the role of aesthetics for such political formations, as Jason Frank's Constituent Moments: Enacting the People in Postrevolutionary America convincingly demonstrates with regard to US American literature.

7. One might describe, in contrast, the imagination of a homogeneous people as an unnecessary fiction.

8. Ernesto Laclau asserts as much in stating that "populist discourse does not simply express some kind of original popular identity; it actually constitutes the latter" (163).

9. We notice this difficulty especially when it obviously fails. The most glaring example is the famous case of Gandhi in the early Civilization series, whose base aggression value is 1 to cast him as the ultimate pacifist, yet the slightest reduction in this numeric value due to diplomatic events (such as the player adopting democracy) would lead the game to misinterpret this negative value 
as the highest positive one, effectively turning Gandhi into a hyperaggressive nuclear warmonger.

10. This structure also corresponds to a more generally Western conception of geopolitics that underlies Civilization as a whole, as Dan Ford shows in his convincing postcolonial critique of the game.

11. For example, the Americans may build the unique units of the B17 bomber and the Minuteman, and their starting bonus is called 'manifest destiny' and grants all land military units +1 sight and gives a $50 \%$ discount when purchasing tiles.

12. 'Ethnopluralism' is anything but pluralistic. The term adopts and mocks a progressive vocabulary but disguises a racist ideology based on the notion that there are 'pure' cultures and ethnicities that each have their territory and should stay there to prevent their corruption.

13. For example: '“I am not a liberator. Liberators do not exist. The people liberate themselves.' Che Guevara" or " II am the Jesus Christ of politics. I am a patient victim, I sacrifice myself for everyone.' Silvio Berlusconi."

14. Bertrand Lucat and Mads Haahr rightly argue that, in Tropico 4, the gameplay usually does not require attention to this level of detail, so that "the determining factor of the ideological narrative of play is the need to keep even these dehumanized masses happy, regardless of their specific proclivities" (10). Yet this does not invalidate the argument that these people do exist as individuals, even if they are rarely perceived as such, since the game thus highlights how their individuality is actually negated in the process of constructing them as 'the people' for the dictator's own purposes.

15. Tyler DeHaven and Chris Hendrickson accordingly read the Vox Populi in Marxist terms as a revolutionary group who ends up as oppressive as those they replace. Stefan Schubert rightly observes that there is no gameplay difference in fighting either of the two, which drives home the point of their parallels on a ludic level on top of the narrative one.

16. The title evokes the US invasion of Panama in 1989-90 under the code name "Operation Just Cause."

17. Notably, the exiled politician Rosa Manuela is introduced in the intro as "populist leader" and not "popular leader," which indicates a certain self-reflexive consideration of this populist imagination.

\section{ABSTRACTS}

The commendable critical tendency to increasingly consider the politics of video games in general is routinely met with resistance on the part of those who insist on their apolitical nature, in parallel to other areas of popular culture. In this contested discourse, it is all the more important to be specific about what it actually means to claim that video games are political, and this essay offers one particular way in which to address this issue. Understanding the political as a way of imagining a community as a political actor through symbolic practices, either in the interest of creating the sovereign of democratic systems or an ethnicity, I argue that video games may employ a populist imagination in constructing 'the people' as a basically unified group (usually in implicitly or explicitly essentialist ways) as much as they may resist or subvert this populist fantasy of homogeneity. I am especially interested in games that dialectically combine both these aspects at the same time by way of dissonances between their representational 
elements and their gameplay. Focusing on strategy games and action games, my examples include Civilization V, Democracy 3, Tropico 4, BioShock Infinite, Just Cause 3, and Far Cry 4.

INDEX

Keywords: populism, politics, video games, unpopular culture

\section{AUTHOR}

\section{SASCHA PÖHLMANN}

Sascha Pöhlmann is professor of North American Literature and Culture at the University of Innsbruck. He is the editor of Playing the Field: Video Games and American Studies and a co-editor of the De Gruyter book series Video Games and the Humanities. His essays include a comparative analysis of David OReilly's Everything and Walt Whitman's "Song of Myself," a phenomenological discussion of mountains in video games, and a critique of the ludic representation of homelessness. 